\title{
Steel-Concrete Composite Construction - New Trend in India
}

\author{
D. Datta \\ (AGM, Institute for Steel Development \& Growth, India) \\ (insdag@rediffmail.com)
}

\begin{abstract}
Presently the human civilization has entered into the fourth generation of innovation from discovery of machines in first phase, discovery of electricity in the second phase and discovery of internet in the third phase. In the present phase some innovations called disruptive innovations, have abolished the prevalent technologies and have changed the human life style radically. In construction sector such disruptive innovations might not have taken place but some advanced technology already popular abroad could be well suited for application to the Indian scenario. Recently, Government of India has targeted to build 20 million urban and 40 million rural houses within just 3/4 years to come, which is achievable only by adopting fast track technology. One of them is Steel-Concrete Composite Design and Construction methodology where the beneficial properties of both Steel and Concrete are optimally used to act together and thereby reduce the material cost and save valuable construction time. India houses about 125 Crores of population, which is sparsely located over a vast area. Mostly the metros with better living opportunities are densely populated because people from less privileged areas throng en mass to these metros. So, it is an arduous task to accommodate such a large volume of migrating people considering all the constraints of expansion possibility of the metros, which necessitates construction of tall buildings. For high-rise buildings Steel-Concrete composite construction is cost-effective. Further, cost is a concept, which varies according to its purpose and Direct Construction Cost is an investment only. The durability, resistance to wind / earthquake tremors, Life Expectancy, better functionality are considered in assessing the Net Construction Cost and Life Cycle Cost of the structures.
\end{abstract}

KEYWORDS - composite construction, direct construction cost, life-cycle-cost, shear connectors.

\section{INTRODUCTION-SOCIO-ECONOMIC DEVELOPMENT VIS.-A-VIS. STEEL CONSUMPTION}

Since consumption of steel is dependent on its use in practically all the sectors of economy including construction, its demand depends on the overall economic performance of a country. There is a general tendency for steel's market share to grow as the national economy develops. It is also likely that steel replaces alternative construction materials as construction work necessitates adoption of faster and sophisticated methodologies. Since 2007-08, Indian steel industry has entered into a prosperous phase with rising demand for steel. In 2014, the world crude steel production reached $1665 \mathrm{mt}$ having a growth of 1\% over 2013 including China as the world's largest crude steel producer $(823 \mathrm{mt})$ followed by Japan $(110.7 \mathrm{mt})$, then USA $(88.2 \mathrm{mt})$ and India $(86.5 \mathrm{mt})$. Rapid rise in production has elevated India to the 3rd largest producer of crude steel in 2015 and the largest producer of sponge iron or Direct Reduced Iron (DRI) in the world. World Steel Association (WSA) has projected Indian steel demand to grow by $6.2 \%$ in 2015 and by $7.3 \%$ in 2016 as compared to global steel use growth of $0.5 \%$ and $1.4 \%$ respectively. As per the report of the Working Group on Steel for the $12^{\text {th }}$ Five Year Plan, the projected growth of manufacturing of steel is $11-12 \%$ from current $8 \%$, which indicates emergence of the rural market for steel currently consuming around $10 \mathrm{~kg}$ per capita against the total consumption of $49 \mathrm{~kg}$ per capita. The National Steel Policy 2005 had envisaged steel production to reach $110 \mathrm{mt}$ by 2019-20. Steel-Concrete composite construction being a steel intensive application, its acceptance is by and large dependent on use of steel in construction.

Special Issue - AETM'16 


\section{Steel-Concrete Composite Construction [1][2][3][4]}

Recently a round table discussion had been organized by CBRI, Roorkee among the concerned agencies including Govt. as well as private and academia on the issues of precast / prefabricated housing based on the present emphasis of GOI towards achieving its mission of "House for all by 2022". GOI has targeted to complete 20 million urban houses and 40 million rural houses within 3/4 years to mobilize a rapid growth of the housing sector. The need of the day is some innovative design methodology, which will reduce Direct as well as Life-Cycle-Costs of construction and will also save the valuable construction time. It is to ensure that the Structural system performs the required design parameters by optimizing the material usage as well as geometric properties of the elements of all the subsystems. Apart from the technical aspects of efficiency, economy and elegance, sustainability and holistic developments also need to be duly considered in design and construction. Steel-Concrete composite construction is such a methodology, which has been popularly followed abroad satisfying all these requirements.

The composite structure includes the Composite Floors, Composite Beams and Composite Columns used individually or in varying combinations to make the design cost-effective and efficient to the desired performance and service requirements. The most commonly used sections are Steel beam anchored to Concrete slab by means of shear connectors of rigid, flexible or bearing types like studs, cut channels etc. and Steel column enclosed within the RCC. Types of the Composite elements are furnished below [5].

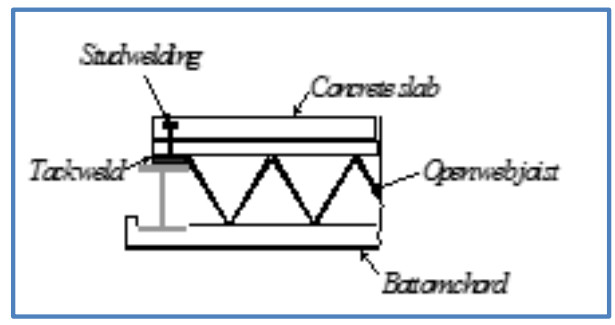

Fig 1: Open Web Joist

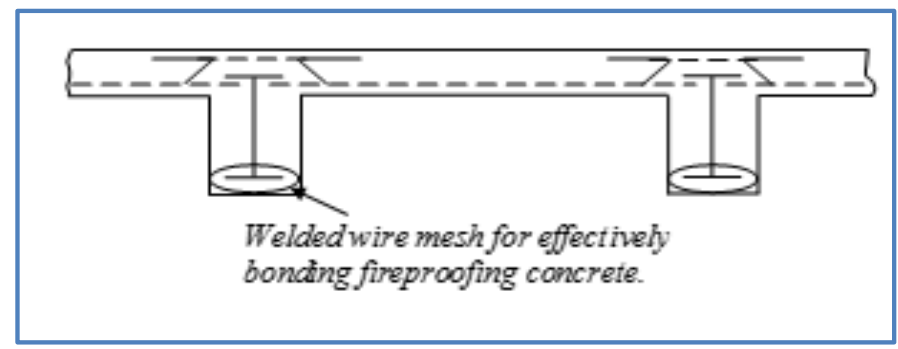

Fig 2 Cross Section of One-Way Slab Floor

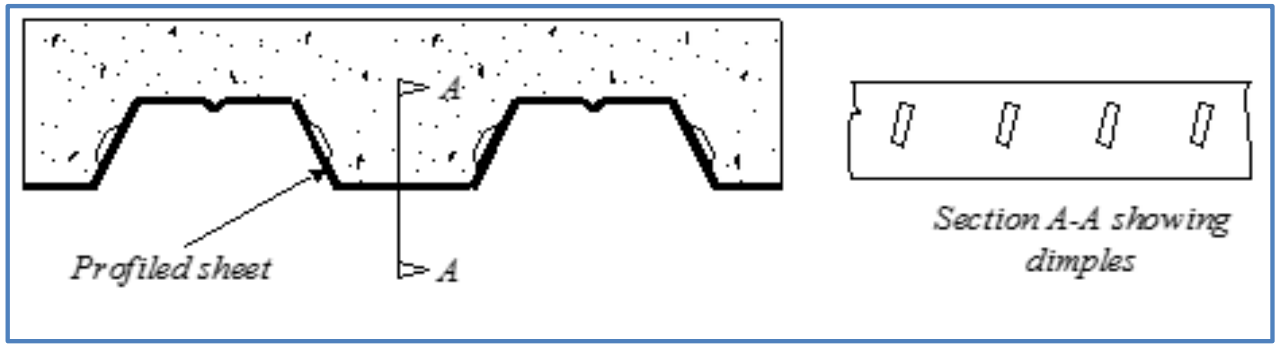

Fig 3: Composite Floor System Using Profiled System 
IOSR Journal of Mechanical and Civil Engineering (IOSR-JMCE)

e-ISSN: 2278-1684, p-ISSN: 2320-334X

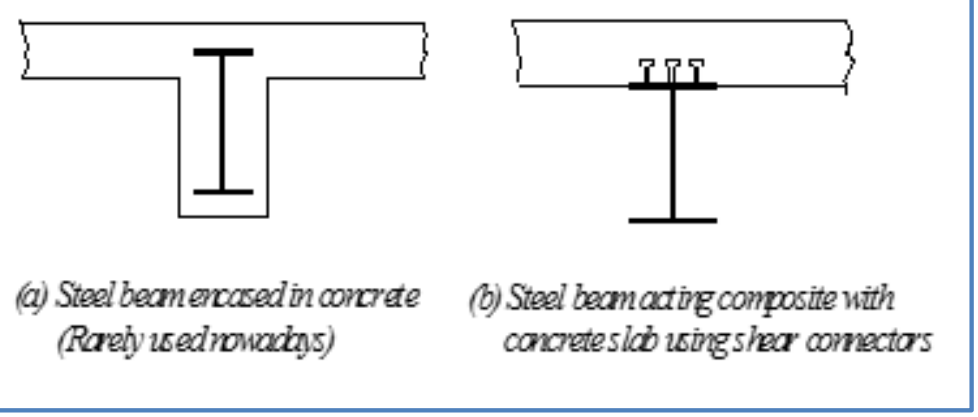

Fig 4: Composite Floor

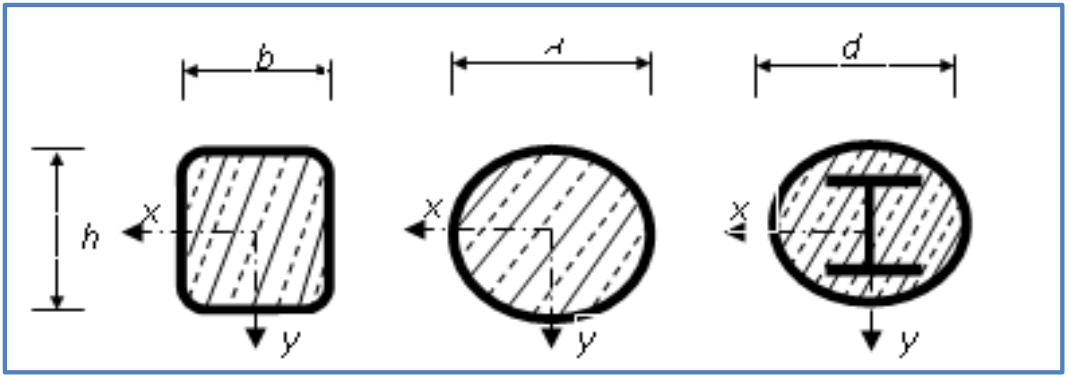

Fig 5: Typical Cross Sections of Concrete Filled Tubular Sections

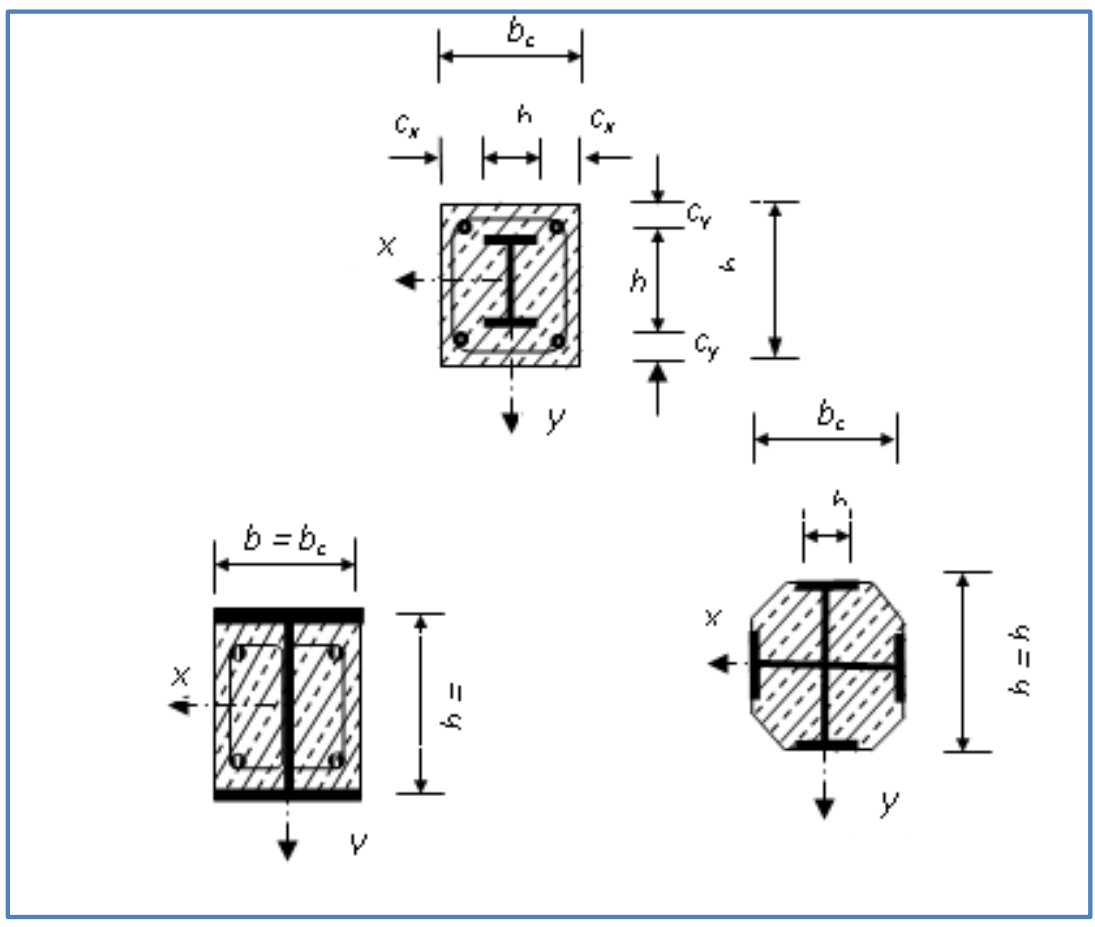

Fig 6: Typical Cross Sections of Fully and Partially Concrete Encased 
Among these elements, floor structures are contributing largely to the overall cost of the buildings because it carries the imposed loads on the structure first and consumes a large quantity of material compared to its strength. But the beam and column structures consume lesser material in comparison to their strengths. Steel and concrete may be used in various combinations to make frame and flooring systems by which their material properties could be exploited to the maximum giving an overall economy of the building system. Along with the primary as well as secondary beams as supports, the flooring system may be integrated with steel beams by use of shear studs, shot fired shear connectors or by deformation of the ribs and the beams may be rigidly connected to the column structures. If the vertical stability of the frame is ensured by provision of vertical bracing systems then the composite beam-column connections may be designed and detailed as pinned connection. During construction necessary precautions need to be taken to ensure the performance of the connections as per the desired design considerations. The conventional Composite Decking system is furnished in figure 7 [6].

In the composite construction, connection between the two dissimilar materials needs to be done with high precision otherwise the composite behavior of the integrated section will not be performed. Typical connection detail of Steel-Concrete composite frame elements is furnished in figures 8 [7].

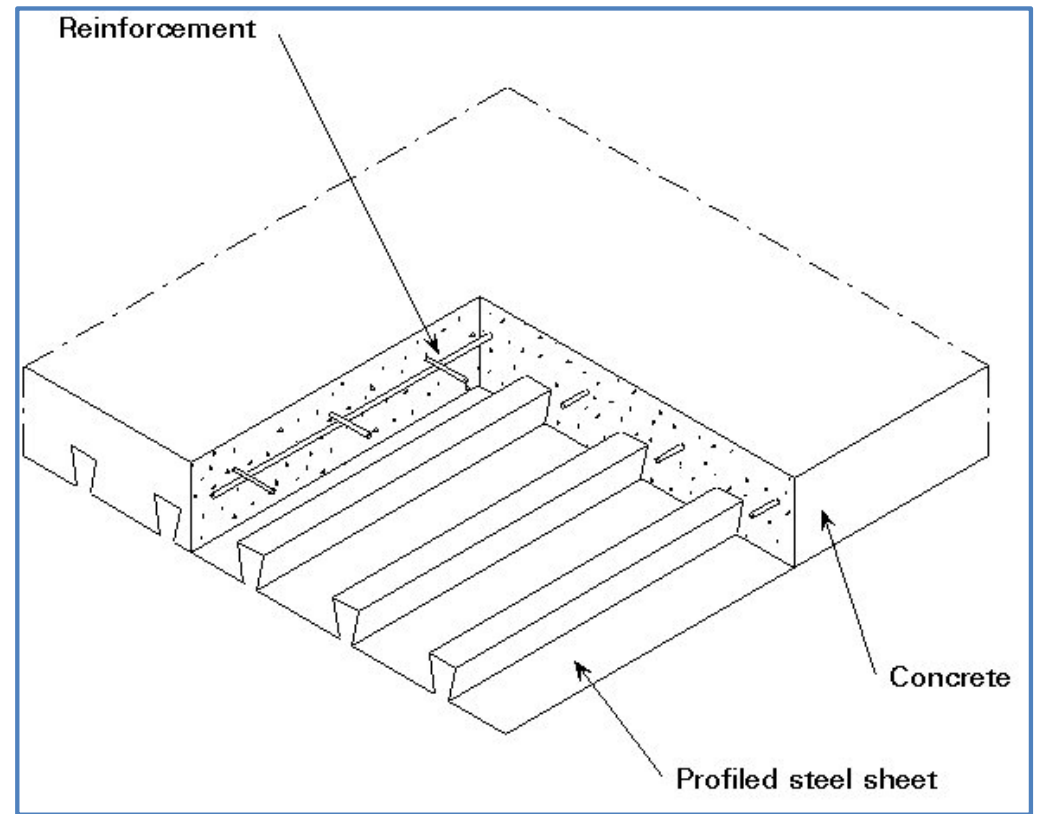

Fig 7: Composite Slab with Profiled Steel Sheet 


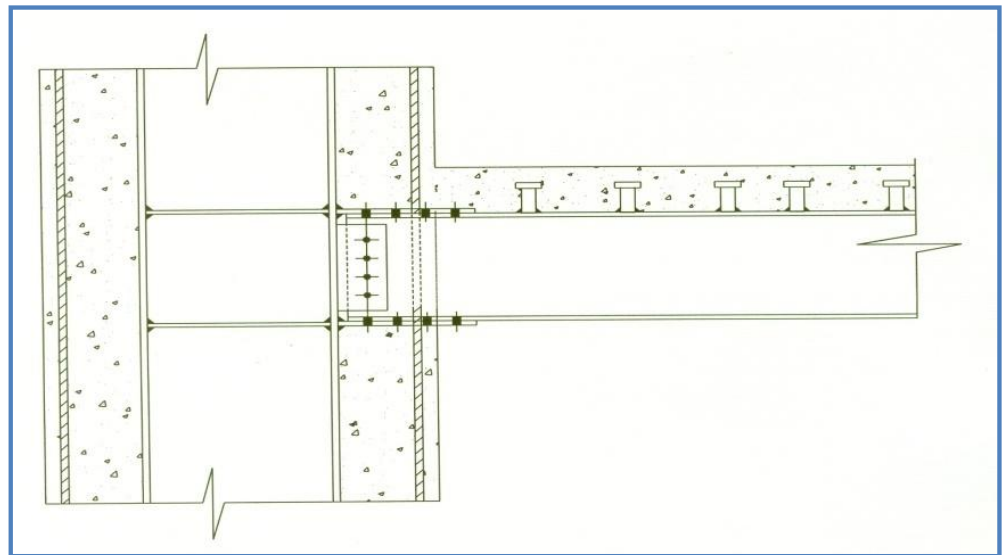

Fig 8: Typical Beam Column Moment Connection Detail

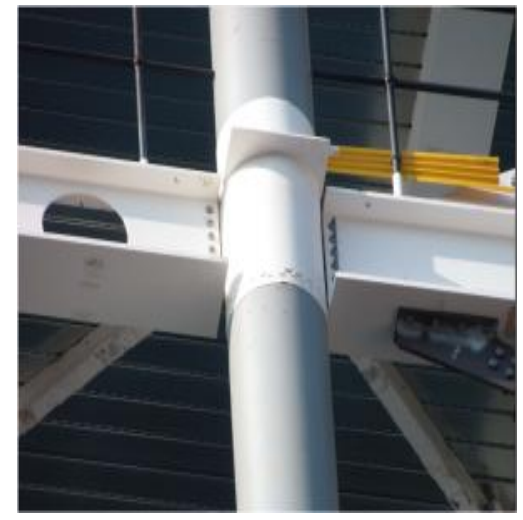

Fig 9: Typical Beam-Column Shear Connection Detail

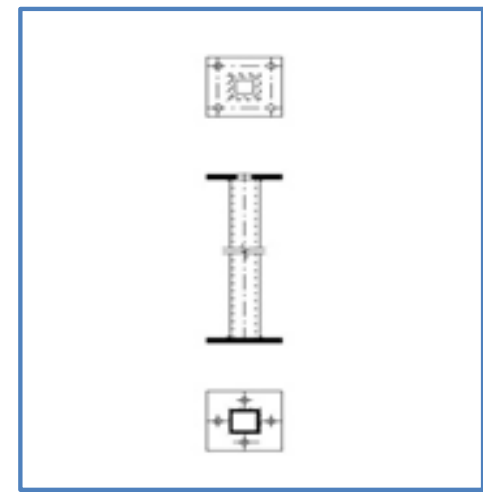

Fig 10: Load Transfer through Head Plate

With this brief description of the salient features of the composite elements, the advantages, limitations and precautions of the composite construction are discussed point-wise as follows.

\section{Advantages Of Steel-Concrete Composite Construction [1][7]}

The numerous advantages of composite construction using steel and concrete are:-

- Most effective utilization of materials viz. concrete in compression and steel in tension.

- High ductility of steel leads to better seismic resistance of the composite section. Steel component can be deformed in a ductile manner without premature failure and can withstand numerous loading cycles before fracture.

- Steel component has the ability to absorb the energy released due to seismic forces through its unique property called ductility.

- Ability to cover large column free area. This leads to more usable space. Area occupied by the composite column is less than the area occupied by the RCC column.

- Faster construction by utilizing rolled and/or pre-fabricated components. Also speedy construction facilitates quicker return on the invested capital.

- Quality of steel is assured since it is produced under controlled environment in the factory under strict Quality Assurance Plan (QAP). More use of steel in composite construction compared to that in RCC structure ensures better quality control. 
- Cost effective, based on life cycle cost analysis since steel structures can be maintained easily and less frequent repairs are required for steel structure.

- Steel is more durable, highly recyclable and hence environment friendly.

- Keeping span/loading unaltered, smaller structural sections are required compared to non-composite construction. Therefore, reduction in overall weight of the composite structure compared to the RCC construction results lesser foundation costs.

- Cost of formwork is lower compared to RCC construction.

- Cost of handling and transportation is less because major part of structure is fabricated in workshop near the site.

- The steel component and hence the steel-concrete composite construction is more resistant against accidental loads compared to RCC construction.

- Composite sections have higher stiffness compared to only steel construction and hence experience lesser deflection than the non-composite steel sections.

\section{Advantage In Cost $[1,7,8,9]$}

In some of the studies carried out by INSDAG, it is found that the Steel-Concrete composite option is costeffective (by about 8-10\%) in Direct Construction Cost when compared with the conventional RCC construction. The Direct Construction Cost is the cost of the construction incurred during the gestation period of the project i.e. it is the investment. Usually the builder borrows capital from commercial banks at the Prime Lending Rate (PLR) of interest, which is considered in these studies as the Interest during Construction (IDC). Due to fast-track construction of composite structures, considerable saving in valuable construction time (about 25-30\% if composite columns and beams only are used and about $40-50 \%$ if composite floor system is also included) could be achieved. The early finish of project will facilitate early return on the borrowed capital and as the least form of return, this amount is considered here as the rental charges $[1,2]$.

\section{NCC $=$ DCC - IDC - RC}

NCC: Net Construction Cost; DCC: Direct Construction Cost; IDC: Interest during Construction over the saved time of construction; RC: Rental Charges (generated earlier due to saving in construction time)

Comparative Cost Study of Different Options Due To Different Sales Price and Rental Charges [1] (B+G+20) Storeyed Building

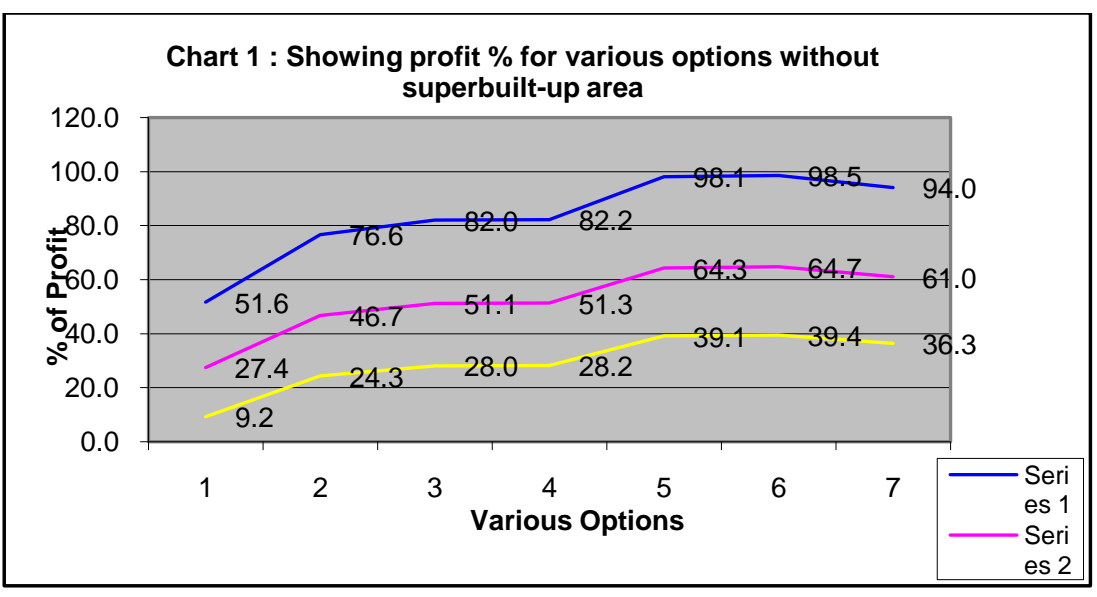


IOSR Journal of Mechanical and Civil Engineering (IOSR-JMCE) e-ISSN: 2278-1684, p-ISSN: 2320-334X
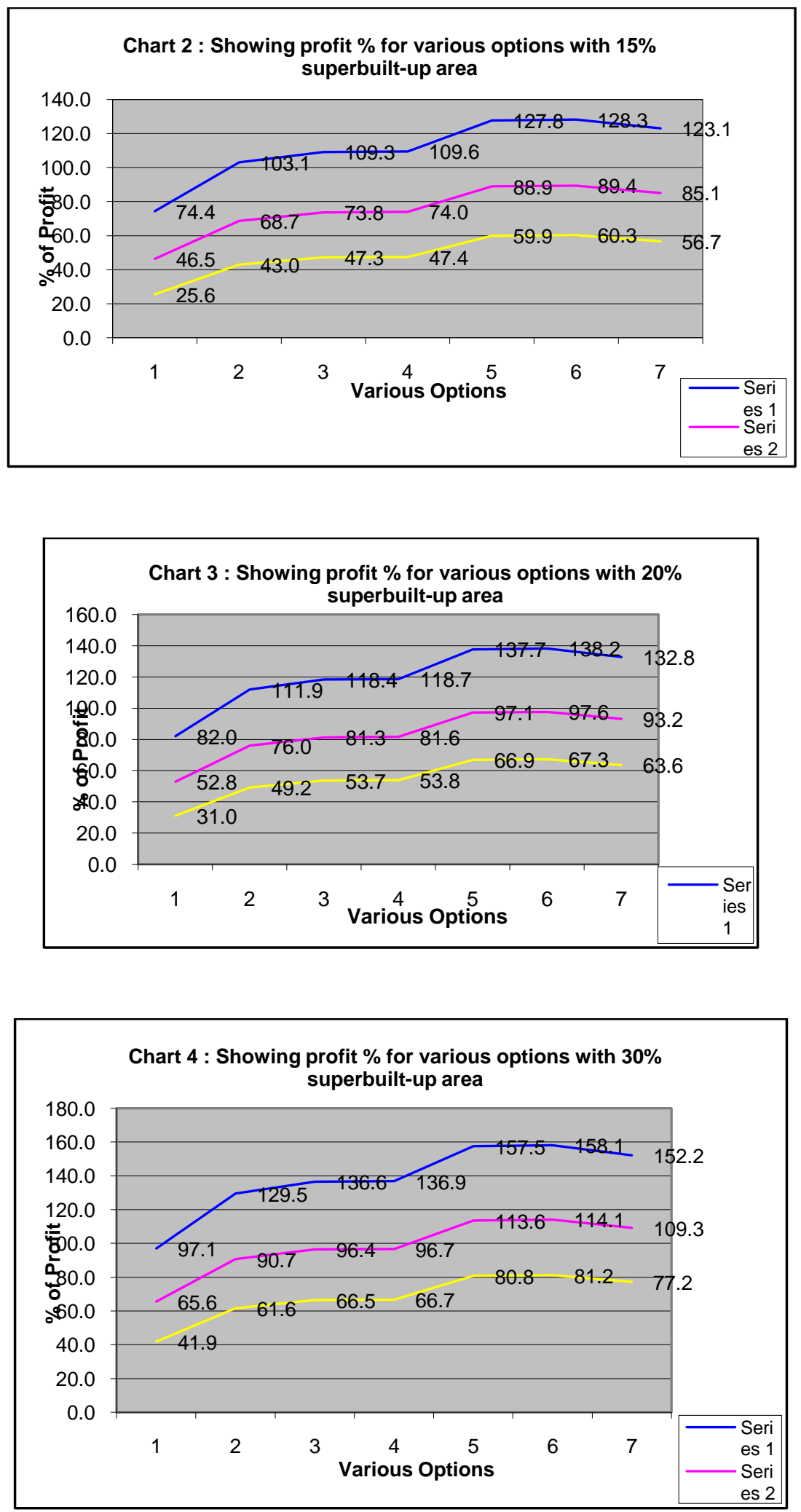

Fig 11: Profit Percentages with Various Options 
Series 1 : For sales price of Rs. 2500/- per sq. ft. and rental charge of Rs. 10/-per sq. ft. Series 2 : For sales price of Rs. 2100/- per sq. ft. and rental charge of Rs. 8/-per sq. ft. Series 3 : For sales price of Rs. 1800/- per sq. ft. and rental charge of Rs. 6/-per sq. ft.

\section{CONCLUSION}

Technological innovations are required to create interest in the builders to keep the real estate business competitive. The use of Steel-Concrete Composite construction methodologies will help the developers to make more profit and the customers could also get more carpet area and durable structure at their affordable price. The benefits of designing Green Buildings had been perceived mainly in terms of total energy saving. Of course, benefit of steel construction compared to other building materials is significant with respect to such considerations also. Americans Institute of Architects (AAI) in their Environmental Resources Guide recommends that Steel is environmentally less harmful than many other competitive options. Generally steel intensive construction being fully recyclable provides improved environmental performance and such construction offers a sustainable development to the society with minimum consumption of energy, minimization of waste and utilization of renewable resources etc. Hence, in the coming decades, steel could be optimally utilized by the Engineers to make the growth of Indian society more user- friendly matching with the National Housing and Habitat Policy and Housing needs of citizens.

\section{REFERENCES}

[1] D. Datta and S. Ghorai, "Multistoreyed Residential Building (B+G+20) Storied with Steel-Concrete Composite construction", Institute for Steel Development \& Growth; Publication No.: INS/PUB/117, 2010.

[2] T.K. Bandyopadhyay, "Basic Concepts in Composite Structures", Refresher Course on Composite Construction using Structural Steel, organized by Institute for Steel Development \& Growth (INSDAG) and Jadavpur University, Kolkata, 2000.

[3] R. Narayanan, "Composite Steel Structures", Advances, Design and Construction, Elsevier, Applied Science, UK, 1987.

[4] Study Report, "Steel Framed Multistoried Buildings", The Economics of Construction in the UK, CONSTRADO, (2), $1985,3$.

[5] R Narayanan, "Structural Steel Design", Teaching Resource: Volume I, II \& III : INSDAG Publication prepared by IIT Madras, Anna University and Structural Engineering Research Centre (SERC), Chennai.

[6] D. Datta and A. Guha, "Guidebook for Design of Embossed Profiled Sheets acting as Composite Deck", Institute for Steel Development \& Growth; Publication No. INS/PUB/079, 2005.

[7] D. Datta and S. Ghorai, "Multistoreyed Buildings with Steel-Concrete Composite Construction - (G+3) \& (G+6)", Institute for Steel Development \& Growth; Publication No.: INS/PUB/132, 2013.

[8] T.K. Bandyopadhyay, "Life-Cycle-Analysis of Steel-Intensive Green Buildings", Green Engineering; Defining the Principles, Florida, USA, 2003.

[9] D. Datta \& S. Chanda, "Life Cycle Cost Analysis of Buildings", Institute for Steel Development \& Growth; Publication No. INS/PUB/129, 2012. 